\title{
Educational Programs Development, Using Intervention Mapping Protocol and Kern Model in Primary Health Care Setting to Prevent Elders Abuse: A Randomized Controlled Trial Study.
}

Sonia Oveisi ( $\nabla$ soveisi@razi.tums.ac.ir)

Qazvin University of Medical Sciences Qazvin Medical School https://orcid.org/0000-0003-3106-8043

Forozan Olfati

Qazvin University of Medical Sciences Qazvin School of Nursing and Midwifery

Shima Jahed

Qazvin University of Medical Sciences Qazvin School of Nursing and Midwifery

\section{Research article}

Keywords: Intervention Mapping, Elder Abuse Prevention, Primary Health Care

Posted Date: July 8th, 2019

DOI: https://doi.org/10.21203/rs.2.11074/v1

License: (c) (i) This work is licensed under a Creative Commons Attribution 4.0 International License.

Read Full License 


\section{Abstract}

Background: Several studies have focused on to find out the factors that may improve psychological, physical well-being, and quality of life among elders and prevent their abuse. Objectives: We investigated the impact of developing educational programs, using Intervention Mapping (IM) protocol and Kern Model in Primary Health Care Setting to prevent elder abuse. Methods: The integrated educational package was provided using both the IM protocol and Kern Model. The family members of the eighty elderly women were trained once a week for 4 sessions. The self-administrated Elder Abuse Questionnaire (EAQ) was completed before and after intervention by elderly women. The linear mixed model was used for the comparison of elder abuse frequency in two groups of control and trail. Results: The data of this study indicated that our intervention resulted in reduction in frequency of psychological and financial abuse $(F=127.12, p<0.005$; and $F=16.53, p<0.07$ respectively) and neglect $(F=95.4 ; p<0.005)$. None of the elders reported any physical abuse. Conclusion: This study showed that, the developed integrated educational package improves elder abuse and specifically it is tailored to the education of family members of the elderly women

\section{Background}

By the year 2050, the number of the elders is estimated to increase by $20 \%$ which will be around 2.5 billion of the world wide population $(1,2)$. These changes imply a need for more understanding the elderly quality of life (3-5). In this view, several studies have focused on to find out factors that may improve psychological, physical well-being, and quality of life in this group of population (6). Elderly mental health which is an important component of wellbeing, has been neglected and is largely ignored among families in the communities (7). Family members suffering from mental disorders such as anxiety, depression and feelings of burden (8-11) are a serious threat for abusing those aged 60 or above (12). The World Health Organization (WHO) states that " EA is a single or repeated act, or lack of appropriate action, occurring within any relationship where there is an expectation of trust which causes harm or distress to an old person." Such abuses are generally included: physical, psychological, sexual, and financial abuse and also neglect $(13,14)$ resulting in shorten of life expectancy in the victims of elders (15). Many researchers investigated the prevalence of elder abuse and realized that there is a wide range of $0.1-10 \%$ elder abuse in most countries $(7,16,17)$. The most common complaint was about the neglect abuse (18).

Attempts to apply behavioral theory to family conflicts dates back to 1960s (19) and the design of intervention programs began in the late 20th century (20). There is a strong evidence that social-learningbased educations as either: primary, secondary, or tertiary interventions (21) are effective by using multidisciplinary and collaborative approaches (22) with a wide range of family problems including socio-economic, ethnic backgrounds, and the cultural practice impact $(23,24)$.

There are several educational intervention programs. In primary or "universal educational programs" do not require that an individual be either at risk or showing any signs of disorder. An advantage of universal 
programs is that no selection procedures are needed and thus stigmatization is unlikely to result (25-28). Although, universal interventions are strategies that target whole communities, it is very important to provide a family needs tailored and reusable educational package. For this purpose, we created new approaches to provide educational packages using learning theories, motivational learning, and process models for designing an educational program $(29,30)$. We introduced an integrated educational package, a proven six-step model to develop medical education (Kern model) and a stepwise process of theory and evidence-based health education program (IM protocol) in primary health care settings (31-33). This educational package includes several integrated tasks from the problem identification to problem-solving.

The Iranian elder populations are not exempted from EA $(34,35)$. A few researchers have declared that old women are the majority of victims (1). Elderly women often do not report these issues due to fear of their families (36), however, the other researchers indicate that gender is no risk factor for EA (7).

Generally, it seems that the old women need more supportive program than men to promote their social well-being, specifically, in countries in which the traditional culture is dominant.

Although, elders in Iran, routinely are referred to health centers for medical check, but no educational program in terms of elder abuse concepts is provided for patients and their families in theses health centers. Thus, an adequate intervention program should be provided considering the social and cultural context of Iranian elderly women, their family and community (37). Therefore, the aim of this study was to investigate the role of integrated educational package (Kern model \& IM protocol) in primary health care settings to engage and provide a preventive intervention to family members of the elderly women. We hypothesized that the integrate educational package would improve elders abuse concepts knowledge in primary health care setting and elders would report the reduction in EA frequency.

\section{Methods}

Design: This randomized controlled trial study was conducted in Qazvin province from August to December 2017. Convenience sampling by visiting health care centers was performed and based on the number of old people receiving medical services. The calculation of sample size was based on the study conducted by Alon, S. 2014 (38) in which $\alpha=0.05, \beta=0.2, p 1=70 \%$ (variable of psychological abuse before intervention), p2 $=50 \%$ (reduction in abuse after intervention). Then the calculated sample size was 80 elderly women. The inclusion criteria were: being an elderly woman of 60 or above; willingness to participate in the study; full consciousness of the time and place; and the ability to respond to the questions in the questionnaire. The exclusion criteria were: possibility of not being available during the period of the study in study area, and failing to participate in all consultation sessions. After advertisement and face to face information sessions 95 elderly women recruited for the study. Fifteen elders did not pass criteria of the study and by one of the health worker who was blind to the study, 80 subjects were randomly allocated into interventional and control groups using Balanced Block Randomization method (AABB, ABBA,..) with 20 blocks. Therefore; participants, data collectors, and the analyzer of data were blind to the study. 
Participants: Eighty elderly women aged 60 years or above receiving health care services from health centers of Tehran, Iran, were invited for participation in our study. The study was approved by ethic committee of Qazvin University of Medical Sciences and researcher obtained a written consent from participant of the study.

Outcomes: The frequency of physical, psychological, and financial abuse, and also neglect were considered as main outcomes which have been measured by the EA questionnaire completed by elderly women in two phases. Firstly, elderly women completed the questionnaire, then the family members of the elderly women were invited to take part in the educational program. After two months, the post intervention EA questionnaire was completed by the elderly women.

Materials: The design of educational package was a first priority considering both the Intervention Mapping (IM) protocol and Kern Model. Six steps of the integrated IM model and Kern model are: $\varangle$ ) problems analysis by identifying what needs to be changed, General Needs Assessment, and Needs assessment for targeted learners (family member of the elderly women) using a short questionnaire aimed at identifying the family member's knowledge about EA concepts: a) key determinants of EA, and b) a definition of EA based on the information obtained from a literature review of EA, caregivers, primary health care workers, and elders' family members; $\varangle$ ) the definition of program objectives to identify which beliefs should be targeted by the intervention, the selection of Educational Strategies, adequate theories, and practical applications for the effectiveness of selected methods tailored to the specific needs of the family member of the elderly women. In addition, performance objectives were specified in terms of how many times elder abuse behavior of family members have been improved as the effects of our educational package; $\varangle$ ) the design of the intervention program to integrate the practical applications into an organized program by identifying program users and supporters. During the design of the intervention, the concepts of EA were formulated and the intervention protocols were completed; $\varangle$ ) the selection of the adequate Educational Strategies based on theories and methods to plan the intervention program (providing pamphlet, giving the lecture and consults). This Educational Strategy is likely to create the expected changes in the EA were identified; $\varangle$ ) the development of a plan for adoption and implementation; and $₫$ ) the development of an evaluation plan using the EA questionnaire to assess the effectiveness of the educational package considering the study design, study population, randomization procedure, outcome measures, and statistical analysis. (39-41). (Table 1)

Measures: The self-report elder abuse questionnaire used in this study examined the frequency of elder abuse and includes 17 questions scored on a Likert scale: (Never $=1)$, (Once $=2)$, (Twice $=3)$, (Three times =4), (Four times =5), (Five times =6), (Six times =7), (Seven times and more=8). It measures the complaint of neglect, physical, psychological and financial abuse against the elderly. Its reliability and validity were examined in a study conducted in Qazvin, Iran, (34). The reliability of this questionnaire was 0.73 as measured by Cronbach's alpha. The first part of the questionnaire examined demographic information, e.g. age, marital status, primary caregiver, level of education, accompanying diseases, level of income, and the status of home ownership. 
Intervention: Four consecutive sessions were performed once a week based on the educational package which consists of the following four stages (table1).

Statistical analysis: First, we calculated demographic variables by mean $\pm S D$ and Number (percent). Then, normality tests were used to determine if main outcomes are well-modeled by a normal distribution by Kolmogorov-Smirnov Test. As our data were not normal, the Linear Mixed Model was used to compare quantitative variables, and the chi-squared test was used for comparing the qualitative variables. Level of significance was set at $0.05 \%$.

\section{Results}

The loss to follow up was 6 from the experimental and 9 from the control group. (Fig 1)

The youngest participant in the control group aged 60 , and the oldest aged 89 years by mean $\pm S D(69.16$ $\pm 7.43)$. In the intervention, the youngest and eldest participants respectively aged 60 and 95 by mean \pm SD $(70.55 \pm 8.56)$; (T-test $=48.0$, P-value $=0.69)$

Table 3 shows the distribution of frequency of level of education of the elderly. Based on this table, $82.4 \%$ in the interventional group and $77.4 \%$ in the control group had no formal education.

Table 4 shows the mean SD of the score of neglect behavior, financial abuse, psychological abuse based on the linear mixed model which were differed significantly. Finally, the meanSD of the score of physical abuse demonstrate no significant difference between the interventional and control groups ( $p$ value $=0.35$ ).

\section{Discussion}

The present study was conducted to examine the effects of integrated educational package for family members of elderly women to prevent elder abuse. The results of this study showed that our intervention based on the integrated educational model package can improve family member's behavior towards elders who reported the reduction of frequency of neglect, financial and psychological abuse. Several studies supported our findings indicating that social workers have main role in reducing abuse by considering the family as a system, identifying the needs of the families, decreasing stress in families members, solving communication problems, and increasing the families potential function for taking care of the elders $(27,28,42)$. Also, results of our study are consistent with the finding of Khanlary et al., who evaluated the effectiveness of social workers intervention in reducing elder abuse. They found that families' member in an intervention group demonstrated greater improvement in terms of psychological, and financial abuse compared to those in a non-intervention group. Their intervention included five sessions with a cognitive-behavioral approach for families. Yet, similar to our finding, they showed that the physical abuse index has not been changed after their intervention (35). Also another study reported that the healthcare workers demonstrated having responsibility for the identification of elderly women who are victims of physical and psychological abuse and can provide appropriate interventions for them 
(43). However, healthcare workers showed that they need to receive specific training programs on EA because of a lack of awareness and perception regarding the reporting procedures (44). These interventions should be designed more compatible with cultural issues in order to strengthen social supports, ethical values, and family integrity (45) with considering various intervention. Results of three studies about the screen, prevention, and treatment of EA showed that it requires various interventions such as individual counseling, legal intervention, inter-professional disciplines, and provision of supportive services for victims of neglect as global violence interventions $(38,46,47)$.

Among different type of elderly abuse, psychological abuse and its consequence is the most important. Heravi et al. reported that among cases that were suffered from psychological abuse related to family dysfunction, $43.3 \%$ of the intervention group had significant improvement compared to control group. This study was conducted on 30 old women and their families visiting the health centers. Their 6 sessions intervention were unstructured and the content of sessions were based on the interaction between families and their elders. Although our teaching material was different from theirs, this study has supported our results that family members need special support groups (48). Another study declared that family conflict was positively associated with increased psychological distress (49), therefore, we declare that our intervention may be effective because of improving family conflict. Our integrated educational package has focused to change the knowledge, attitudes, and belief of family members about concept and definitions of elder abuse because the public support a fairly broad definition of elder abuse and that this definition of elder abuse was fairly stable over time (50).

\section{Conclusion:}

Results of this study indicated that integrated educational package for the family member of elderly women may decrease psychological abuse and neglect. This decrease was significant compared to the control group, however, the elderly women did not mention any physical abuse before and after the intervention in this group. This educational package is re-useable program which is based on the Iranian culture and context. Therefore, we suggest that healthcare workers in Iran health centers provide this program for all families in order to promote family members' knowledge and attitude about EA. Moreover, our paper explained how to provide a standard educational package to aim at decreasing EA. among communities with a wide range of cultures by detecting needs, choosing a suitable educational strategy, and evaluating it.

\section{Limitation and suggestion:}

The aim of this study was to provide the reusable and cultural based educational package, therefore, a pilot randomized control trial was done to test our intervention without follow up for a long time and multiple questionnaires to detect valid responses. As a result, the size of the population studied did not have power to detect some changes, such as physical abuse. Also, it was not clear whether these 
changes are sustained over time, and the use of only one instrument which was not separately validated on this population might be a problem. We suggest that the others complete some questionnaires for healthcare workers, family members, and the elderly as the EA instruments repeatedly with a larger sample size.

\section{List Of Abbreviations}

IM: Interventional Map

EA: Elder Abuse

WHO: World Health Organization

\section{Declarations}

Ethics approval and consent to participate: Medical Research Ethics Committee of the Qazvin University of Medical Science approved this study on 8 November 2016 and the number was:

IR.QUMS.REC.1395.184. We received the written consent of participants to conduct our study. This study was registered at the Iranian Registry of Clinical Trials (IRCT2017061234496N1).

Consent for publication: Not applicable.

Availability of data and materials: The datasets used and/or analyzed during the current study are available from the corresponding author. Also, it is presented as additional supporting files.

Funding: Qazvin University of Medical science funded this study by providing facilities for data management. For example: The cost of duplicating questionnaire, a simple catering for participants, and the publication of final thesis.

Authors' contributions: a) conception and design by SJ, FO, and SO; b) implementation of intervention and collection of Data by SJ. C) Analysis of data by SO; d) interpretation of data by FO and SO; e) drafting the article by FO and SO; f) revising it critically for important intellectual content by SO; g) final approval of the version to be published by SO. All authors have read and approved the manuscript. 


\section{Competing interests: Not applicable.}

\section{Acknowledgments: This article was extracted from a postgraduate dissertation on counseling in midwifery research. Authors express hereby acknowledge to old women and their family participating in this research.}

\section{Reference}

1. Yon Y, Mikton C, Gassoumis ZD, Wilber KH. The Prevalence of Self-Reported Elder Abuse Among Older Women in Community Settings: A Systematic Review and Meta-Analysis. Trauma, Violence, \& Abuse. 2017:1524838017697308.

2. Strausbaugh LJ. Emerging health care-associated infections in the geriatric population. Emerging infectious diseases. 2001;7(2):268.

3. Ahrari S, Moshki M, Bahrami M. The Relationship Between Social Support and Adherence of Dietary and Fluids Restrictions among Hemodialysis Patients in Iran. Journal of Caring Sciences. 2014;3(1):11-9.

4. Feizabadi M, Nakhoda M, Delbari A. Research Databases and Geriatrics and Gerontology Journals: The Comparison of Databases and Their Covered Journals. Iranian Journal of Ageing. 2016;11(2):358-69.

5. Yaghoobzadeh A, Sharif Nia H, Hosseinigolafshani Z, Mohammadi F, Oveisi S, Torkmandi H. Associated Factors of Ageing Perception among Elderly in Qazvin, 2015. Journal of Gerontology. 2017;1(4):1-10.

6. Collins KA. Elder maltreatment: a review. Archives of pathology \& laboratory medicine. 2006;130(9):1290-6.

7. Acierno R, Hernandez MA, Amstadter AB, Resnick HS, Steve K, Muzzy W, et al. Prevalence and correlates of emotional, physical, sexual, and financial abuse and potential neglect in the United States: The National Elder Mistreatment Study. American journal of public health. 2010;100(2):292-7.

8. Jane M. Survival is not Enough: Violence Against Older Women in Australia. Violence Against Women. 2003;9(12):1478-89.

9. Anetzberger GJ. Caregiving: Primary cause of elder abuse? Generations. 2000;24(2):46.

10. Wang JJ, Lin MF, Tseng HF, Chang WY. Caregiver factors contributing to psychological elder abuse behavior in long-term care facilities: a structural equation model approach. Int Psychogeriatr. 2009;21(2):314-20. 
11. Orfila F, Coma-Solé M, Cabanas M, Cegri-Lombardo F, Moleras-Serra A, Pujol-Ribera E. Family caregiver mistreatment of the elderly: prevalence of risk and associated factors. BMC public health. 2018;18(1):167.

12. Randel J, German T, Ewing D. The ageing and development report: poverty, independence and the world's older people: Routledge; 2017.

13. Krug EG, Mercy JA, Dahlberg LL, Zwi AB. The world report on violence and health. The lancet. 2002;360(9339):1083-8.

14. ohn M Halphen J M, Carmel B Dyer M,FACP, AGSF. elder mistreatment. up to date. 2012.

15. Johnson SS, Paiva AL, Cummins CO, Johnson JL, Dyment SJ, Wright JA, et al. Transtheoretical model-based multiple behavior intervention for weight management: effectiveness on a population basis. Prev Med. 2008;46(3):238-46.

16. Laumann EO, Leitsch SA, Waite LJ. Elder mistreatment in the United States: Prevalence estimates from a nationally representative study. The Journals of Gerontology Series B: Psychological Sciences and Social Sciences. 2008;63(4):S248-S54.

17. Feltner C, Wallace I, Berkman N, Kistler CE, Middleton JC, Barclay C, et al. Screening for intimate partner violence, elder abuse, and abuse of vulnerable adults: evidence report and systematic review for the US Preventive Services Task Force. JAMA. 2018;320(16):1688-701.

18. Tolan P, Gorman-Smith D, Henry D. Family violence. Annu Rev Psychol. 2006;57:557-83.

19. Falloon IR. Handbook of behavioural family therapy: Routledge; 2015.

20. Baker AA. Granny battering. Nurs Mirror Midwives J. 1977;144(8):65-6.

21. Teresi JA, Burnes D, Skowron EA, Dutton MA, Mosqueda L, Lachs MS, et al. State of the science on prevention of elder abuse and lessons learned from child abuse and domestic violence prevention: Toward a conceptual framework for research. Journal of elder abuse \& neglect. 2016;28(4-5):263-300.

22. Reis M, Nahmiash D. When seniors are abused: an intervention model. Gerontologist. 1995;35(5):66671.

23. Biglan A. The need for a more effective science of cultural practices. The Behavior Analyst. 2016;39(1):97-107.

24. Biglan A. Translating what we know about the context of antisocial behavior into a lower prevalence of such behavior. Journal of Applied Behavior Analysis. 1995;28(4):479-92.

25. Dadds MR. Early intervention approach for children and families at risk for psychopathology. Comprehensive handbook of psychotherapy: Cognitive-behavioral approaches. 2002;2:51-72. 
26. Holzer P, Higgins J, Bromfield L, Higgins D. The effectiveness of parent education and home visiting child maltreatment prevention programs. Australian Institute of Family Studies. 2006.

27. Ganser HG, Munzer A, Witt A, Plener PL, Muche R, Rosner R, et al. Effectiveness of manualized case management on utilization of evidence-based treatments for children and adolescents after maltreatment: A randomized controlled trial. Child Abuse Negl. 2017;67:371-82.

28. Hinsliff-Smith K, Feakes R, Whitworth G, Seymour J, Moghaddam N, Dening T, et al. What do we know about the application of the Mental Capacity Act (2005) in healthcare practice regarding decision-making for frail and older people? A systematic literature review. Health Soc Care Community. 2017;25(2):295308.

29. Reigeluth CM. Instructional theory for education in the information age. Instructional-design theories and models: Building a common knowledge base. 2009;3:387-99.

30. Keller JM. First principles of motivation to learn and e3-learning. Distance education. 2008;29(2):17585.

31. Kern DE, Bass EB, Thomas PA, Howard DM. Curriculum development for medical education: a six step approach: JHU Press; 1998.

32. Thomas PA, Kern DE, Hughes MT, Chen BY. Curriculum development for medical education: a six-step approach: JHU Press; 2015.

33. Strijk JE, Proper KI, van der Beek AJ, van Mechelen W. The Vital@ Work Study. The systematic development of a lifestyle intervention to improve older workers' vitality and the design of a randomised controlled trial evaluating this intervention. BMC Public Health. 2009;9(1):408.

34. Oveisi S, Karimi R, Mahram M. Note From Iran: Self-Reported Elder Abuse in Qazvin, 2012. Journal of Elder Abuse \& Neglect. 2014;26(3):337-40.

35. Khanlary Z, Maarefvand M, Heravi Karimoo M, Biglarian A. Study of the Effect of Social Work Intervention on the Elderly Abuse Reduction. Iranian Journal of Ageing. 2016;10(4):102-11.

36. Perel-Levin S, Organization WH. Discussing screening for elder abuse at primary health care level by Silvia Perel-Levin. 2008.

37. Abdi A, Tarjoman A, Borji M. Prevalence of elder abuse in Iran: a Systematic review and meta-analysis. Asian Journal of Psychiatry. 2019;39:120-7.

38. Alon S, Berg-Warman A. Treatment and Prevention of Elder Abuse and Neglect: Where Knowledge and Practice Meet-A Model for Intervention to Prevent and Treat Elder Abuse in Israel. Journal of Elder Abuse \& Neglect. 2014;26(2):150-71. 
39. Bartholomew Eldredge LK, Markham CM, Ruiter RAC, Fernández ME, Kok G, Parcel GS. Planning health promotion programs: Jossey-Bass Inc.; 20162016.

40. Bartholomew LK, Parcel G, Kok G. Intervention Mapping Designing Theory and Evidence-Based Promotion Programs. MountainView, California: Mayç eld Publishing Company; 2001.

41. Kok G, Gottlieb NH, Peters G-JY, Mullen PD, Parcel GS, Ruiter RAC, et al. A taxonomy of behaviour change methods: an Intervention Mapping approach. Health Psychology Review. 2016;10(3):297-312.

42. Newman BM NP. Development through life. Cengage Learning; 2017 Apr 12.

43. Mouton CP, Rodabough RJ, Rovi SL, Brzyski RG, Katerndahl DA. Psychosocial effects of physical and verbal abuse in postmenopausal women. Ann Fam Med. 2010;8(3):206-13.

44. Corbi G, Grattagliano I, Sabbà C, Fiore G, Spina S, Ferrara N, et al. Elder abuse: perception and knowledge of the phenomenon by healthcare workers from two Italian hospitals. Internal and Emergency Medicine. 2019.

45. Dong X, Chang E-S, Wong E, Simon M. Perceived Effectiveness of Elder Abuse Interventions in Psychological Distress and the Design of Culturally Adapted Interventions: A Qualitative Study in the Chinese Community in Chicago. Journal of Aging Research. 2013;2013:9.

46. Russo A, Reginelli A, Pignatiello M, Cioce F, Mazzei G, Fabozzi O, et al. Imaging of Violence Against the Elderly and the Women. Seminars in Ultrasound, CT and MRI. 2019;40(1):18-24.

47. Kar HL. Acknowledging the victim to perpetrator trajectory: Integrating a mental health focused trauma-based approach into global violence programs. Aggression and Violent Behavior. 2018.

48. Heravi Karimoi M, Jadid Milani M, Faghihzadeh S. The effect of family counseling programs on prevention of psychological abuse of elderly women. Hayat. 2005;11(2):79-86.

49. Kwon S. Perceived discrimination, family and spousal relationships, and psychological distress among Asian Americans: Testing mediation and moderation effects. The Social Science Journal. 2019.

50. Morgan E, Johnson I, Sigler R. Public definitions and endorsement of the criminalization of elder abuse. Journal of Criminal Justice. 2006;34(3):275-83.

\section{Tables}

Table 1: Questions in the Elder abuse instruments to detect 4 type of Elder Abuse 
Items for measuring physical abuse were:

Have you been hit, kicked, punched, or otherwise by someone within the past two months? If yes, how many times.

Has anyone close to you tried to hurt you or harm you within the past two months? If yes, how many times. Items for measuring neglect were:

Were you sad or lonely often? (within the past two months) If yes, how many times.

Have you been hungry within the past two months? If yes, how many times.

Have you been in conditions that you need help and ask for help but ignored by your family members? (within the past two months) If yes, how many times.

Have you been in a situation where you were scared at home? (within the past two months) If yes, how many times.

Have you had thoughts of taking your life, even if you would not really do it? (within the past two months) If yes, how many times.

\section{Items for measuring financial abuse were:}

Has anyone taken things that belong to you without your O.K.? (within the past two months) If yes, how many times

Have you been forced to get cash to your family members? (within the past two months) If yes, how many times.

Have you been asked to sign papers you did not understand? (within the past two months) If yes, how many times.

\section{Items for measuring psychological abuse were:}

Has anyone forced you to do things you didn't want to do within the past two months? If yes, how many times.

Have you experienced living in fear because somebody systematically has threatened you? (within the past two months) If yes, how many times.

Has anyone close to you ever completely refused to talk to you or ignored you for days at a time, even when you wanted to talk to them within the past two months? If yes, how many times.

Have you been verbally threatened or insulted by others within the past two months? If yes, how many times.

Has someone screamed or yelled at you within the past two months? If yes, how many times.

Have you been afraid of your family members? ( within the past two months) If yes, how many times.

Table 2. The intervention implemented based on the educational package 


\begin{tabular}{|c|c|c|}
\hline $\begin{array}{l}\text { Duration of } \\
\text { Session }\end{array}$ & Content of Sessions & Sessions \\
\hline $45 \mathrm{~min}$ & $\begin{array}{l}\text { Introduction } \\
\text { Giving information about this educational program } \\
\text { Defining EA concepts, indicators, and consequences } \\
\text { Setting the time of the next session }\end{array}$ & $\begin{array}{l}\text { First } \\
\text { Sessions }\end{array}$ \\
\hline $45 \mathrm{~min}$ & $\begin{array}{l}\text { Giving information about the common problems associated } \\
\text { with the process of Ageing } \\
\text { Definition of different types of EA } \\
\text { Question and answer about how to encourage them to re- } \\
\text { evaluate their behavior } \\
\text { Introspection, explaining the risks of the current behavior, } \\
\text { reflection } \\
\text { Define his/her goals } \\
\text { Setting the time of the next session }\end{array}$ & $\begin{array}{l}\text { Second } \\
\text { Sessions }\end{array}$ \\
\hline $45 \mathrm{~min}$ & $\begin{array}{l}\text { Teaching interpersonal skills for a healthy communication with } \\
\text { the elderly } \\
\text { Evaluating the advantages and disadvantages of their behavior } \\
\text { and abilities } \\
\text { confirming one's preparedness for changing, and enhancing } \\
\text { one's confidence in his/her abilities } \\
\text { Group discussion for resolving issues and answering questions }\end{array}$ & $\begin{array}{l}\text { Third } \\
\text { Sessions }\end{array}$ \\
\hline $40 \min$ & $\begin{array}{l}\text { Review of previous topics } \\
\text { Giving pamphlets to present the other family members } \\
\text { Well-practiced actions for achieving their goals } \\
\text { How to maintain the new behavior } \\
\text { Thanking the families }\end{array}$ & $\begin{array}{l}\text { Fourth } \\
\text { Sessions }\end{array}$ \\
\hline
\end{tabular}


Table 3. Comparing the demographic variables of elderly women in two control and intervention groups by $\chi 2$ measure.

\begin{tabular}{|c|c|c|c|c|c|c|c|}
\hline \multirow{3}{*}{$\begin{array}{c}\text { Variables } \\
\text { Elders' education }\end{array}$} & & \multicolumn{2}{|c|}{$\begin{array}{l}\text { Intervention } \\
\text { group }\end{array}$} & \multicolumn{2}{|c|}{$\begin{array}{l}\text { Control } \\
\text { group }\end{array}$} & \multirow{2}{*}{$\begin{array}{c}\text { Chi- } \\
\text { square } \\
3.61\end{array}$} & \multirow{2}{*}{$\begin{array}{c}\text { P_value } \\
0.65\end{array}$} \\
\hline & & $\mathrm{N}$ & $\%$ & $\mathrm{~N}$ & $\%$ & & \\
\hline & $\begin{array}{l}\text { No years of } \\
\text { education }\end{array}$ & 28 & 82.35 & 24 & 77.4 & & \\
\hline \multirow{6}{*}{$\begin{array}{c}\text { Elders' marital } \\
\text { status }\end{array}$} & $\begin{array}{c}\text { High school and } \\
\text { less }\end{array}$ & 5 & 14.71 & 6 & 16.1 & & \\
\hline & College and more & 1 & 2.94 & 2 & 6.5 & & \\
\hline & Total & 34 & $\% 100$ & 31 & $\% 100$ & & \\
\hline & Married & 22 & 64.7 & 21 & 67.7 & 79 & 0.06 \\
\hline & Single & 12 & 35.3 & 10 & 32.3 & & \\
\hline & Total & 34 & $\% 100$ & 31 & $\% 100$ & & \\
\hline \multirow{5}{*}{ Elders' diseases } & $\begin{array}{l}\text { Cardio-pulmonary } \\
\text { disease }\end{array}$ & 6 & 17.7 & 5 & 16.1 & 1.93 & 0.92 \\
\hline & Diabetes & 10 & 29.4 & 11 & 35.5 & & \\
\hline & $\begin{array}{l}\text { High blood } \\
\text { pressure }\end{array}$ & 11 & 32.4 & 10 & 32.3 & & \\
\hline & Miscellaneous & 7 & 2.5 & 5 & 16.1 & & \\
\hline & Total & 34 & $\% 100$ & 31 & $\% 100$ & & \\
\hline \multirow[t]{4}{*}{ Primary caregiver } & Husband & 19 & 55.9 & 21 & 67.7 & 1.37 & 0.5 \\
\hline & Children & 7 & 2.6 & 6 & 19.4 & & \\
\hline & Nobody & 8 & 23.5 & 4 & 12.9 & & \\
\hline & Total & 34 & $\% 100$ & 31 & $\% 100$ & & \\
\hline \multirow{3}{*}{$\begin{array}{c}\text { Status of Home } \\
\text { Ownership }\end{array}$} & Owned & 34 & 100 & 30 & 96.8 & 1.11 & 0.29 \\
\hline & Rented & 0 & 0 & 1 & 3.2 & & \\
\hline & Total & 34 & $\% 100$ & 31 & $\% 100$ & & \\
\hline \multirow[t]{3}{*}{ Level of income } & Low & 13 & 38.2 & 12 & 38.7 & 9.8 & 0.99 \\
\hline & Moderate \& high & 21 & 61.8 & 19 & 61.3 & & \\
\hline & Total & 34 & $\% 100$ & 31 & $\% 100$ & & \\
\hline
\end{tabular}


Table 4. Comparing the frequency of four types of the Elder Abuse (mean \pm SD) among elderly women in two control and intervention groups using Linear Mixed Model measure.

\begin{tabular}{|c|c|c|c|c|c|c|c|}
\hline Variables & group & Time & Mean $\pm S D$ & $\min$ & $\max$ & $p$-value & $F$ \\
\hline \multirow[t]{4}{*}{ Neglect } & \multirow[t]{2}{*}{ Intervention } & Before & 2.977 .2 & 0 & 10 & $\mathrm{P}<0.005$ & 95.4 \\
\hline & & After & $2.1 \pm 2.29$ & 0 & 9 & & \\
\hline & \multirow[t]{2}{*}{ Control } & Before & $1.55 \pm 2.16$ & 0 & 7 & & \\
\hline & & After & 2.14 & 0 & 7 & & \\
\hline \multirow[t]{4}{*}{ Financial abuse } & \multirow[t]{2}{*}{ Intervention } & Before & $0.57 \pm 1.42$ & 0 & 7 & 0.07 & 16.53 \\
\hline & & After & $0.49 \pm 1.15$ & 0 & 7 & & \\
\hline & \multirow[t]{2}{*}{ Control } & Before & 0.2376 .0 & 0 & 5 & & \\
\hline & & After & 0.2376 .0 & 0 & 5 & & \\
\hline \multirow[t]{4}{*}{ Psychological abuse } & \multirow[t]{2}{*}{ Intervention } & Before & $4.4 \pm 4.44$ & 0 & 21 & $<0.005$ & 127.12 \\
\hline & & After & $3.23 \pm 3.34$ & 0 & 16 & & \\
\hline & \multirow[t]{2}{*}{ Control } & Before & $3.48 \pm 3.6$ & 0 & 14 & & \\
\hline & & After & $3.5 \pm 3.4$ & 0 & 14 & & \\
\hline \multirow[t]{4}{*}{ Physical abuse } & \multirow[t]{2}{*}{ Intervention } & Before & 00 & 0 & 0 & 0.13 & 2.29 \\
\hline & & After & 00 & 0 & 0 & & \\
\hline & \multirow[t]{2}{*}{ Control } & Before & 0.170 .03 & 0 & 1 & & \\
\hline & & After & 0.170 .03 & 0 & 1 & & \\
\hline
\end{tabular}

\section{Figures}


The CONSORT diagram showing the flow of participants through each stage of a randomized trial.

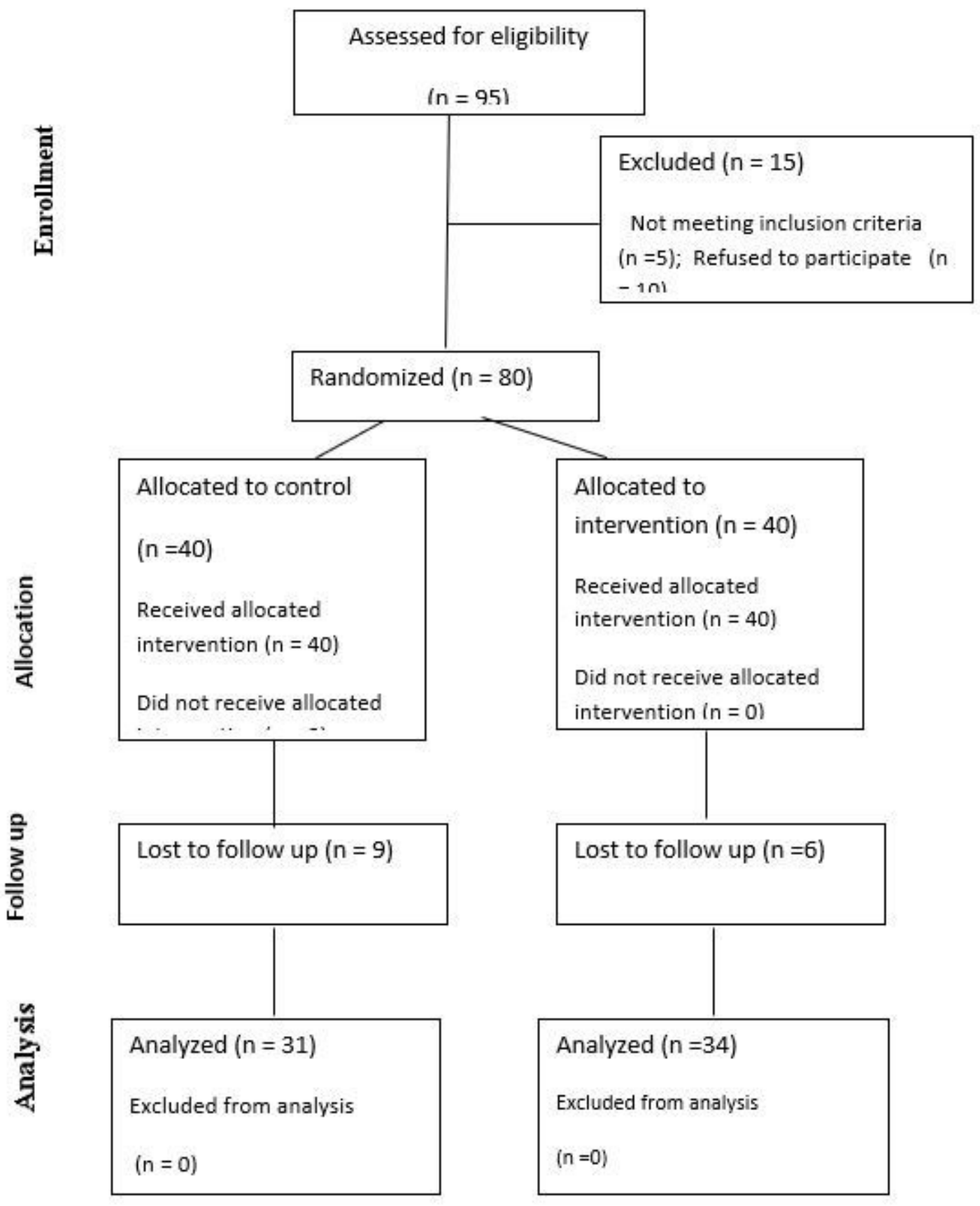

Figure 1

The CONSORT diagram showing the flow of participants through each stage of a randomized trial.

\section{Supplementary Files}

This is a list of supplementary files associated with this preprint. Click to download.

- salmandcasecontorl.sav 
- CONSORT2010Checklist1.doc 